\title{
A DICOTOMIA DO PÚBLICO/PRIVADO EM HANNAH ARENDT E JÜRGEN HABERMAS: INTERAÇÕES E REFLEXÕES A LUZ DA TEORIA CRÍTICA CONTEMPORÂNEA (1)
}


ao espaço e função da outra. A privatização do que é público, e a exposição do que é privado, acaba por uma nova perspectiva ao que se tinha como dicotomia indicando novas fronteiras. Esse artigo propõe-se a apresentar uma reflexão sobre a influência que o conceito de esfera pública de Hannah Arendt e Jürgen Habermas possui sobre a ideia de público e privado na teoria da filosofia política atual. Para sua realização dessa explanação, foi feito os seguintes passos: compreender os conceitos de esfera pública em Hannah Arendt e Jürgen Habermas, apresentar a influência que os conceitos desses dois pensadores exercem na filosofia política, sistematizar os elementos em relação a perspectivas de influências do debate político filosófico atual.

PALAVRAS-CHAVE: Dicotomia. Jürgen Habermas. Hannah Arendt. Filosofia Política.

\title{
THE PUBLIC / PRIVATE DICHOTOMY IN HANNAH ARENDT AND JÜRGEN HABERMAS: INTERACTIONS AND REFLECTIONS IN THE LIGHT OF CONTEMPORARY CRITICAL THEORY
}

\begin{abstract}
In both moral philosophy, politics and philosophy of language, the idea of public space is thought as a means of interaction and interlocution between individuals in the process of circulation and political and collective decision making. It is not only a space in the literal sense, but in the metaphorical sense, the meeting of the citizens, who each argue their ideas and opinions, and debate the ideal for a society, is a 'place' that can be virtual or physicist. The private therefore represents the particular space of intimacy, with well-defined roles within a hierarchy where the whole spectrum of individual construction is developed, this construction is also influenced by moral and religious aspects. Relations between the public and private spheres demarcate modern society. The function of one sphere ends up merging with the space and function of the other. The privatization of what is public, and the exposition of what is private, ends up in a new perspective to what one had as a dichotomy indicating new frontiers. This article proposes to present a reflection about the influence that the concept of public sphere of Hannah Arendt and Jürgen Habermas has on the idea of public and private in the theory of the current political philosophy. For the realization of this explanation, the following steps were taken: to understand the concepts of the public sphere in Hannah Arendt and Jürgen Habermas, to present the influence of the concepts of these two thinkers in political philosophy, to systematize the elements in relation to the perspectives of debate influences political philosophy
\end{abstract}

KEYWORDS: Dichotomy. Jürgen Habermas. Hannah Arendt. Politcal Phylosophy. 


\section{INTRODUÇÃO}

Na filosofia política contemporânea a dicotomia espaço público/privado foi objeto de estudos de filósofos como Hannah Arendt e Jürgen Habermas, que contribuíram e desenvolveram com suas reflexões diversos desdobramentos do pensamento ético-político atual sobre esses espaços. Ao se dialogar com Arendt e Habermas possibilita-se um reconhecimento de um modelo de esfera pública como sociedade civil distinta tanto do Estado como do mercado e essencial para a criação de uma comunidade ativa de cidadãos capazes de sustentar uma sociedade democrática, colaborando na construção de atuações discursivo-ativas de sujeitos políticos nessas esferas e também em debates atuais sobre este tema.

A partir da analise do conceito de Arendt sobre esfera pública, a detectamos como uma esfera significativa nas atividades humanas, que nos insere no debate sobre o que representa esse espaço para o sujeito, como o seu discurso está correlacionado a sua ação neste espaço e como sujeito político ativo, busca o consenso pelas necessidades compartilhadas em coletivo. Já nos estudos de Jürgen Habermas o discurso é protagonista na esfera pública o autor explana todo o processo da formação de uma esfera pública burguesa e sua relação delimitada com o espaço privado. O debate em função do discurso não só se revela como ponto de formação de deliberações democráticas como também pressão institucional para resoluções importantes ao bem estar social. As análises que partem desses conceitos vislumbram discussões e caracterizações sobre esses espaços que em alguns momentos se mesclam e demarcam seus objetos e funções atravessando décadas.

$\mathrm{Na}$ pesquisa para construção desse texto, realizou-se o estudo da obra "A condição Humana" (2014) de Hannah Arendt e "Direito e Democracia entre facticidade e validade" (1997) "Mudança estrutural da esfera pública" (1962) de Jürgen Habermas, procurou-se analisar e compreender o conceito dos dois filósofos, reconhecer e delimitar as influências e caracterizações de cada conceito, para um entendimento consistente. Posterior a esse entendimento, se iniciou um processo de sistematização dessas ideias e reconhecimento de reverberações nos estudos de teoria critica e suas possíveis intersecções e reverberações atuais.

\section{O DOMÍNIO DO PRIVADO: O ESPAÇO FAMILIAR}

Para a filósofa Hannah Arendt, o primeiro reconhecimento de espaço público é na pólis grega, onde a vida política era exercida em um espaço chamado Ágora ${ }^{l}$. Neste local, ocorria o 
debate, o discurso, exercitava-se a democracia, a vida em comum, os cidadãos eram considerados livres, discursavam, argumentavam, onde todos são considerados iguais.

Arendt em "A condição humana" (2014) caracteriza e conceitua o espaço público e privado, partindo de uma análise do modelo grego de sociedade de esferas bem definidas, porém ao decorrer da caracterização, ela também tece críticas como o fato de ambos os espaços perderem seu sentido original e dissolverem-se, transformando-se em instâncias que praticamente não se diferenciam, segundo ela. Mergulhada no debate sobre o desaparecimento da esfera pública e da esfera privada, Arendt analisa que o político não pode mais sobreviver e que, como consequência, emerge o social. Nesse contexto, as esferas do público e do privado possuem definiçõos muito claras e que posteriormente foi se deteriorando pelo chamado advento do social, que seria o surgimento da sociedade de massas e a inserção dessa sociedade no domínio público, segundo Arendt.

Tendo como pressuposto que só a ação é exclusiva do homem e que depende da presença de outros homens, Arendt critica a tradução do conceito de Aristóteles, de 'zoon politikon $^{2}$, como animal social feita por alguns autores. Para a filósofa, a perda da ideia de animal político e a aceitação da noção de animal social revelam o esquecimento da concepção original grega de política. $\mathrm{O}$ conceito de homem como animal político está relacionado à vida em comum e, portanto, à ação.

Segundo a filósofa, a capacidade de organização política - que se opõe à mera associação natural entre humanos - teve sua expressão máxima na constituição da cidadeestado, em que cada cidadão, além de sua vida privada, pertencia à vida política em que fazia uso da ação e do discurso. A liberdade situa-se na esfera política, caracterizava-se a pólis por somente conhecer "iguais", enquanto na família encontrava-se a desigualdade. A autora desenvolve essa ideia demonstrando que o espaço da família é o espaço do comando do chefe do lar, figura sempre masculina e normativa, onde se estabelece uma hierarquização. Por exemplo, nesse trecho é bem clara a noção do que significava o espaço privado:

O que distinguia a esfera familiar era que nela os homens viviam juntos por serem compelidos por suas necessidades e carência. A força compulsiva era a própria vida, os penates, os deuses do lar, eram, segundo Plutarco, 'os deuses que nos fazem viver e alimentar o nosso corpo'; e a vida, para sua manutenção individual e sobrevivência como vida da espécie, requer a companhia de outros. O fato de que a manutenção individual fosse a tarefa do homem e a sobrevivência da espécie fosse a tarefa da mulher no parto, eram sujeitas à mesma premência da vida. Portanto, a comunidade natural do lar decorria da 
necessidade: era a necessidade que reinava sobre todas as atividades exercidas no lar (ARENDT, 2014, p. 40-41).

$\mathrm{Na}$ vida privada ou íntima, era o espaço para se a realizar a própria manutenção da sobrevivência, onde o chefe da casa, o pai, comandava quase se assemelhando a um desposta (rei). Segundo Arendt, no domínio privado existia uma subordinação pulsante, onde esse mesmo chefe era responsável pela decisão de opinar por todos os membros. Estabelece-se divisão de papéis, masculino e feminino, ambos relacionados à existência e a necessidade de manutenção da mesma, a mulher é a encarregada do lar e a 'sobrevivência' da espécie, o homem se responsabilizava pelo labor (trabalho artesanal agricultura) e sustento, ambos os papéis caracterizam-se pela subordinação a manutenção dessa reprodução e sobrevivência, portanto, só seria livre aquele que se desvinculasse dessa necessidade.

No espaço privado não havia igualdade e liberdade. A liberdade e o exercício da politica se realizavam e equacionavam no domínio público, nesse trecho Arendt esclarece a divisão: “ $\mathrm{O}$ domínio da pólis, ao contrário, era a esfera da liberdade, e se havia uma relação entre essas duas esferas era que a vitória sobre as necessidades da vida no lar constituía a condição óbvia para a liberdade na pólis.” (ARENDT, 2014, p. 37.). Na reflexão de SANTOS:

A distinção entre a esfera pública e a esfera privada era tão marcante que Arendt afirma a existência de um abismo entre elas no mundo grego. Todas as atividades - cuja finalidade se constituía na garantia da sobrevivência e no sustento do indivíduo, isso é, no seu processo vital não eram dignas da esfera política. A vitória sobre as necessidades da vida em família é que permitiu o aparecimento da polis, pois a política não visa à manutenção da vida. Dessa forma, "no que tange aos membros da polis, a vida no lar existe em função da boa vida na polis" (ARENDT, 2008, p. 47). A excelência em si - areté para os gregos - era reservada à esfera pública, pois (não apenas a presença de outros) o partilhar da vida comum é necessário para atingi-la (SANTOS, 2002, p. 225).

A esfera política é pertencente ao domínio público, o espaço privado era considerado o espaço obscuro, onde só o que era irrelevante permanecia, o que era relevante, se apresentava no domínio público. Segundo a análise da filósofa, a boa vida na polis só existia pela manutenção da vida no lar, porém o lar era propriedade do homem e essa propriedade deveria ser preservada para que ele adentrasse o domínio público.

\section{O DOMÍNIO DO PÚBLICO: O COMUM}


Para Arendt, o termo "público" remete a dois fenômenos: em primeiro lugar, significa que tudo o que vem a público pode ser visto e ouvido por todos e tem a maior divulgação possível. Nesse sentido, quando um pensamento ou um sentimento é divulgado, o privado torna-se de acesso público. Contudo, esse fenômeno é garantido pela condição de que os outros têm de partilhar a realidade do mundo e de nós mesmos. O espaço público se caracteriza por um espaço de valorização da pluralidade humana, onde o compartilhamento mútuo acontece, ele não deve ser entendido por apenas uma perspectiva, é um espaço comum a todos, onde há igualdade. O público é o espaço do visível, "tudo o que vem a público pode ser visto e ouvido por todos" (ARENDT, 2014, p. 49), a visibilidade na esfera pública é o que constitui a realidade.

A esfera pública para Arendt é o espaço comum a todos, local de reconhecimento dos mesmos objetivos, onde ação e discurso se unem e tomam forma para a construção do "mundo comum", onde os sujeitos se articulam e partilham a formação do "sentido comum", há a realização política neste espaço. É um espaço de organização política, onde se possibilita vislumbrar a própria realidade, o homem necessita relacionar-se com o outro para comprovar sua própria existência e o mundo que o rodeia e isso remete ao segundo ponto que embasa a ideia de público:

Em segundo lugar, o termo 'público' significa o próprio mundo, na medida em que é comum a todos nós e diferente do lugar que nos cabe dentro dele. Este mundo, contudo, não é idêntico à terra ou à natureza como espaço limitado para o movimento dos homens e condição geral da vida orgânica. Antes, tem a ver com o artefato humano, com o produto de mãos humanas, com os negócios realizados entre os que, juntos, habitam o mundo feito pelo homem. Conviver no mundo significa essencialmente ter um mundo de coisas interposto entre os que nele habitam em comum, como uma mesa se interpõe entre os que se assentam ao seu redor; pois, como todo intermediário, o mundo ao mesmo tempo separa e estabelece uma relação entre os homens (ARENDT, 2014, p. 62).

Percebe-se a realização da existência humana pela aparência (no sentido ser percebido), a relação do ser humano com o outro, confirma sua existência no mundo, pois é o lugar em que os homens podem mostrar quem realmente são. Assim, em benefício dessa possibilidade "e por amor a um corpo político que a propiciava a todos, cada um deles estava mais ou menos disposto a compartilhar do ônus da jurisdição, da defesa e da administração dos negócios públicos” (ARENDT, 2014, p. 51). Nesse sentido, Telles afirma: 
A dissolução desse espaço público significa a perda de um "mundo comum" que articula os homens numa trama visível feita por fatos e eventos tangíveis no seu acontecimento e que se materializa na comunicação intersubjetiva, através da qual as opiniões se formam e os julgamentos se constituem. Nesse caso, a dissolução do espaço público significa mais do que a perda de um espaço comum entre os homens. Pois essa perda significa também a dissolução do "senso comum", comprometendo esta capacidade de discernimento que a compreensão e o julgamento exigem, enquanto "maneira especificamente humana" de se fazer a experiência da realidade (TELLES, 1990, p. 4).

O pensamento político grego se baseava da distinção entre o domínio público e o domínio privado, todavia, essa distinção, que aos gregos era essencial, é para a contemporaneidade bastante confusa, já que nos habituamos com outro domínio que eclodiu junto com a modernidade: o social. Enquanto a esfera pública estava vinculada com a possibilidade de o homem alcançar sua excelência, a esfera privada representava a necessidade do homem (masculino), suas carências, desejos e aspirações. É importante lembrar que na privatividade o homem estava impossibilitado de aparecer, de ver e ser visto, de ouvir e ser ouvido, o lar não era espaço para a política, pois no lar se fazia presente a necessidade e submissão, ao passo que na política é imprescindível que haja liberdade. Assim, o lar era concebido enquanto esfera pré-política, na qual imperava a força e a violência, instrumentos para saciar as necessidades da vida:

Viver uma vida inteiramente privada significa (...) estar privado da realidade que advém do fato de ser visto e ouvido por outros, privado de uma relação "objetiva" com eles decorrente do fato de ligar-se e separarse deles mediante um mundo comum de coisas, e privado da possibilidade de realizar algo mais permanente que a própria vida. A privação da privatividade reside na ausência de outros; para estes, o homem privado não aparece, e, portanto, é como se não existisse (ARENDT. 2014, p. 67).

Porém, embora viver na esfera privada significasse viver privado de coisas essenciais a uma vida verdadeiramente humana, por outro lado, sem possuir um lar, um homem não podia participar dos assuntos do mundo porque não tinha nele um lugar que fosse propriamente seu. Então, ainda que a privatividade tenha um forte caráter de não liberdade, era condição aos homens possuir um espaço que pudessem denominar como seu, para assim então poder participar da vida pública. Tal questão se faz mais compreensível ao se retomar ao fato de que o lar é o espaço no qual as necessidades primárias são correspondidas, sem necessidade de reconhecimento ou mudança. Deixando seus desejos no espaço privado o homem enfim pode se 
dedicar à vida política, de acordo com a análise de Arendt do modelo de sociedade grega.

\section{O ADVENTO DO SOCIAL}

O processo da chegada da modernidade coincidiu historicamente com a transformação da preocupação individual com a propriedade privada em preocupação pública. A promoção da sociedade acontece ao mesmo tempo em que ocorre o declínio da família, que de certa forma é desejada por grupos sociais correspondentes. O surgimento da sociedade de massas indica:

[...] que os vários grupos sociais foram absorvidos por uma sociedade única, tal como as unidades familiares haviam sido agregadas por grupos sociais; com o surgimento da sociedade de massas a esfera do social atingiu finalmente, após séculos de desenvolvimento, o ponto em que abrange e controla, igualmente e com igual força, todos os membros de determinada comunidade (ARENDT, 2014, p. 50).

A ideia principal na sociedade de massas, de homem como animal social e não animal político, ameaça à extinção da humanidade, uma vez que a sociedade tem um caráter monolítico em que "o conformismo só dá lugar a um único interesse e uma única opinião" (ARENDT, 2014, p. 65). Como prova disso, a nova esfera social transformou as comunidades em sociedade de operários, concentrados em torno da única atividade necessária para manter a vida que, para Arendt, é o trabalho (ou labor em outras traduções):

A contradição entre o privado e o público, típica dos estágios iniciais da era moderna, foi um fenômeno temporário que trouxe a completa extinção da própria diferença entre as esferas privada e pública, a submersão de ambas na esfera do social. [...] a esfera pública porque se tornou função da esfera privada, e a esfera privada porque se tornou a única preocupação comum que sobreviveu (ARENDT, 2014, p. 79).

No momento em que o público torna-se privado e o privado torna-se público, ambas as esferas desaparecem. Arendt lembra que não apenas a extinção da esfera pública é preocupante, como também a ausência da privatividade, na medida em que a abolição da propriedade privada significa a eliminação do lugar 'ideal' possuído na terra por uma pessoa. Na concepção da autora, a vida privada não tem um sentido totalmente negativo: "Sua discussão não é travada no sentido de desqualificar a vida privada, mas de estabelecer o seu lugar e definir as fronteiras entre duas formas distintas de existência social [...] duas formas diferentes de se fazer a experiência da sociedade." (TELLES, 1990, p. 5).

Assim, a extinção da diferença entre a esfera privada e a esfera pública tal como existia 
no mundo grego, a transferência das preocupações privadas para a política e a valorização da esfera privada como fenômeno social constituem questões a serem mais bem compreendidas e discutidas. Na perspectiva de Hannah Arendt, segundo a comentadora Telles:

A perda do espaço público significa a perda dessa condição de igualdade que apenas a liberdade pública pode construir. Excluídos ou privados desse espaço, os homens ficam fixados nas suas diferenças, enquanto forma de existência 'outorgada' pela natureza. O risco desse processo está no fato de que a diferença - de raça, sexo, etnia etc. - que diz respeito à esfera privada constitua critério político e, portanto, seja elemento definidor na esfera pública. (TELLES, 1990, p. 8)

O fato de os critérios privados adentrarem a esfera pública torna a questão das diferenças como ponto de definição de igualdade e prática democrática, desvirtuando o que a esfera pública representa essencialmente. Os indivíduos se fecham em suas diferenças e priorizam seus desejos individuais buscando sempre realiza-los sem se importar com a partilha do comum a todos, sem deixar de lado a singularidade de cada ser humano.

A ordem imposta no espaço privado é ditada não com base na liberdade, mas em questões tidas como naturais. Isso não significa que a administração do lar não tenha papel nenhum para a formação da cidade, isto é, da polis, a obediência ao chefe de família e a coerção pela força e pela physis constituem a ordem do lar. Deste modo, ambos os domínios, o público e o privado, coexistiam, apesar de ainda haver na compreensão grega um determinado abismo entre ambos.

$\mathrm{Na}$ modernidade que surge aquilo ao qual designamos por sociedade, onde o abismo antes existente entre o lar (privado) e o público passa a ser suprimido. O advento do social se dá enquanto um alargamento do lar ocupando a esfera pública. De certa forma, a sociedade representa o lar em proporções maiores, tem-se um espaço de grandes proporções que possibilita não aquilo pretendido pela esfera pública - a imortalização através da ação e do discurso, mas representa a nivelação de todos os homens, um espaço no qual assumem meramente para a sobrevivência. Não é mais a ação à atividade exaltada, mas o comportamento através da normalização que Arendt chama de sociedade de massas.

Se a compreensão originária da política se destinava à possibilidade de o indivíduo se diferenciar dos demais, o social se baseia na igualdade e no conformismo, na uniformização dos indivíduos, e um dos fatores que auxiliam nisso é o crescimento populacional, posto quanto maior for a população de um corpo político, mais difícil será se opor à massificação das 
atividades, mais esforço será necessário dedicar para se diferenciar da normalização. A sociedade se baseia na completa naturalização dos homens, já havia na esfera do lar a compreensão do homem enquanto um mero animal, ou seja, enquanto outra espécie que habita a terra e busca suprir suas necessidades vitais, no entanto, o que foi feito pelo social foi canalizar para o domínio público o espaço de garantir tanto a sobrevivência individual quanto a continuidade da espécie. A sociedade, assim, tem como função não mais a aparição e a imortalização, mas a simplesmente manter a vida. Diz Arendt:

A indicação talvez mais clara de que a sociedade constitui a organização pública do processo vital encontra-se no fato de que (...) o novo domínio social transformou todas as comunidades modernos em sociedades de trabalhadores e empregados; (...), essas comunidades concentraram-se imediatamente em torno da única atividade necessária para manter a vida. (Naturalmente, para que se tenha uma sociedade de trabalhadores (...) basta que todos os seus membros considerem tudo o que fazem primordialmente como modo de sustentar suas próprias vidas e as de suas famílias.) A sociedade é a forma na qual o fato da dependência mútua em prol da vida, e de mais nada, adquire importância pública, e na qual se permite que as atividades relacionadas com a mera sobrevivência apareçam em público (ARENDT, 2014, p. 56).

A esfera (advento) do social, na medida em que leva ao espaço de aparição as questões concernentes à esfera do lar, não significa uma expansão do público para o privado, mas precisamente o contrário: o privado, antes destinado a não aparecer no mundo comum, surge como um problema da esfera pública. Além disso, o trabalho, e não mais ação, se torna atividade central do domínio público, transformando os cidadãos em uma sociedade de massas que não tem mais em vista o discurso e a ação, apenas a manutenção da sua vida em sentido biológico em detrimento da liberdade política, da capacidade de iniciar sempre algo novo.

Arendt percebe que ao longo da tradição de teoria política, o domínio público e o político são capturados pelas atividades que abrangem a vita activa ${ }^{3}$ questões como: qual a necessidade da política pra a vida humana? Por que só somos políticos e fazemos em coletivo nunca em singular? Permeia a obra 'A condição Humana' da filósofa, ela identifica a era moderna como ruptura entre política, ciência e sociedade, defende a tese de que divisão permitiu a instrumentalização da política, o declínio do domínio público e a perda e o desaparecimento da ação e do discurso, que para a autora são primordiais no exercício e existência da esfera pública ou domínio público como ela denomina, a esfera do social para a autora representa a troca de fundamentação da ação política, onde a necessidade passou a 
ocupar o lugar da liberdade.

\section{A ESFERA PÚBLICA EM JÜRGEN HABERMAS: REFLEXÕES E INTERAÇÕES}

A esfera pública, na concepção habermasiana, é o espaço discursivo e deliberativo, em que todos podem participar, fazendo uso de uma razão esclarecida, exercendo influência sobre o sistema político, e é também, a base para um sistema democrático. Existem grupos excluídos, que não exercem influência sobre a opinião pública, esta, com frequência atende a interesses privados, provenientes de grupos, partidos políticos e pessoas com poder econômico e de influência discursiva e social.

$\mathrm{Na}$ sociedade contemporânea, essas questões críticas permanecem, e em vista disso, Habermas reestrutura o conceito de esfera pública: as teorias da ação comunicativa e da ética do discurso em Habermas valorizam a racionalidade comunicativa, inerente à esfera pública. Essa racionalidade tem potencial normativo para a autonomia dos sujeitos e também para a manutenção da ordem social, porque as leis são fundamentadas através do discurso argumentativo.

Na obra "Direito e Democracia" (1997), Habermas destaca que esta jamais pode ser confundida com alguma instituição, organização ou qualquer estrutura normativa, não é possível delimitar suas fronteiras previamente, ela se constitui como uma estrutura aberta. Em suas palavras: "[...] a esfera pública pode ser descrita como uma rede adequada para a comunicação de conteúdos, tomadas de posição e opiniões; nela os fluxos comunicacionais são filtrados e sintetizados, a ponto de se condensarem em opiniões públicas enfeixadas em temas" (HABERMAS, 1997, p.92).

O filósofo afirma que os atores da esfera pública não podem exercer poder político e não podem coincidir com essa política institucional. A esfera pública, na medida em que não é uma organização, também não constitui necessariamente um espaço institucional, no entanto, da mesma forma que uma organização ou outra forma de realização espacial pode ter uma dimensão abstrata, a esfera pública pode, eventualmente, coincidir com uma estrutura concreta, porém ela é mais complexa do que qualquer contorno que se possa delimitar:

(...) as esferas públicas ainda estão muito ligadas aos espaços concretos de um público presente. Quanto mais elas se desligam de sua presença física, integrando também, por exemplo, a presença virtual de leitores situados em lugares distantes, de ouvintes ou espectadores, o que é possível através da mídia, tanto mais clara se torna a abstração que acompanha a passagem da estrutura espacial das interações simples para a generalização da esfera pública (HABERMAS, 1997, p. 93). 
Sobre a função da esfera pública e a formação da opinião pública, esta desempenha uma função não só de identificar e perceber a realidade e os problemas sociais, mas ela deve principalmente exercer pressão sobre o sistema político a ponto de argumentar e convencer sobre as questões que foram debatidas e problematizadas na esfera. Esta influência ocorre pela força exercida através da construção da opinião pública, sendo esta última formada através do processo de comunicação dentro da esfera, ou seja, quando as opiniões individuais são estabelecidas pelo meio de argumentos, troca de informações e discussões, existe a possibilidade do surgimento de uma ideia comum, um consenso, uma opinião pública comum.

Mas Habermas sugere, ainda, que existem variações na "qualidade" da opinião pública gerada: ocorre que dependendo do grau, mais ou menos racional das argumentações e opiniões propostas, a opinião publica será mais ou menos qualificada. $\mathrm{O}$ critério da qualificação é dado pelo grau maior ou menor de racionalização envolvido na formação desta e não pela expressividade das emoções de cada um. Esta ideia é explicitada no seguinte trecho: "[...] com esse 'mais ou menos' em termos de elaboração 'racional' de propostas, de informações e de argumentos, há geralmente uma variação no nível discursivo da formação da opinião e na ‘qualidade’ do resultado” (HABERMAS, 1997, p. 94). Na tentativa de gerar alguma influência sobre o sistema político, alguns atores podem se colocar de forma centralizada na esfera pública. Segundo o filósofo, grupos estabelecidos e indivíduos com notoriedade na sociedade podem exercer maior convencimento em seus discursos e elaborar com maior facilidade um julgamento ou opinião, mas, sempre será necessário para constituir uma opinião pública de influência política, que haja concordância das outras pessoas, inclusive dos leigos, pois estes também participam da esfera pública.

As pessoas que não estão inseridas em grupos de interesses organizados nem tampouco são especialistas em determinados assuntos, participam da esfera pública produzindo opiniões, consentindo ou não com as ideias formadas pelos segmentos citados, através de suas experiências (vivências) cotidianas. Sobre o público e privado Habermas destaca o seguinte:

[...] Os canais de comunicação da esfera pública engatam-se nas esferas da vida privada - as densas redes de interação da família e do círculo de amigos e os contatos mais superficiais com vizinhos, colegas de trabalho, conhecidos, etc. - de tal modo que as estruturas espaciais de interações simples podem ser ampliadas e abstraídas, porém não destruídas. De modo que a orientação pelo entendimento, que prevalece na prática cotidiana, continua valendo também para uma comunicação entre estranhos, que se desenvolve em esferas públicas complexas e ramificadas, envolvendo amplas distâncias (HABERMAS, 1997, p. 98). 
A esfera pública e a esfera privada não estão desassociadas, pelo contrário, a esfera pública capta e expõe as demandas existentes na esfera privada, problematizando-as e trazendoas para o debate público. A esfera privada, por sua vez, incorpora os debates e agrega informações que influenciam na vida cotidiana e possibilitam refletir sobre a mesma. Também não é o conteúdo das temáticas que separam as duas esferas, Habermas escreve que são as condições de comunicação modificadas que as diferenciam, ou seja, não existe definido os temas que são privados e os que são públicos, o que determina a passagem de um tema privado para uma esfera pública é a capacidade dos atores articularem tal temática num debate que se mostre relevante para o interesse comum.

Os problemas gerados pela sociedade são perceptíveis na vida cotidiana, nas histórias de vida de cada individuo, na medida em que problemas são captados e tematizados na esfera privada, logo poderão ser incorporados nos debates públicos e encaminhados ao sistema político como demanda pública a ser atendida.

Segundo Habermas as associações da sociedade civil "formam o substrato organizatório do público de pessoas privadas que buscam interpretações públicas para suas experiências e interesses sociais" (HABERMAS, 1997, p. 100), porém, ele adverte que é fundamental que a privacidade seja preservada por direitos fundamentais garantidores da livre expressão, livre crença, livre consciência e todos os direitos que fundamentam os direitos civis. Somente com uma esfera privada livre e preservada por direitos é que a esfera pública pode existir.

Habermas caracteriza uma separação de público/privado em dois níveis: no nível dos sistemas e no nível do mundo da vida. No nível dos sistemas, a separação público/privado se dá entre o Estado (sistema público) e a economia oficial capitalista (sistema privado). Já no nível do mundo da vida, a distinção encontra-se entre a esfera pública (espaço da participação política e da formação da opinião) e a esfera privada (família nuclear moderna). Essas separações estão inter-relacionadas devido à institucionalização de papéis específicos que vinculam as diferentes esferas. Assim, o sistema público está vinculado à esfera pública por meio dos papéis do cidadão e depois do cliente (o capitalismo do bem-estar), relações essas realizadas principalmente no ambiente do poder. Paralelamente, o sistema privado e a esfera privada ligam-se pelos papéis do trabalhador e do consumidor, trocas essas realizadas no âmbito do dinheiro.

Pode-se observar que existe um processo de inspiração de Habermas na construção da 
dicotomia de privado e público de Arendt, visualiza-se a aproximação entre o processo comunicativo/discursivo de Habermas com a liberdade e ação (práxis-agir político) na concepção de vida pública de Arendt. O que ocorre é que o conceito de Habermas não só dá continuidade ao conceito já reconhecido de Arendt, mas também propõe o superar no sentido de identificar a colaboração entre o privado e o público como ponto evolutivo, na medida em que e constrói uma proposta de diagnóstico de realidade, que podemos argumentar também como uma visão mais positivada da modernidade, ele percebe o advento do social como fonte de mudanças necessárias a uma dicotomia que já não cabe a estrutura de reivindicações e transformações sociais.

Habermas admite a existência de desigualdade de posições dentro da esfera pública moderna, ele percebe que grupos de interesse podem usar a esfera pública para propagar suas ideias e estratégias de poder e que certas pessoas têm acesso privilegiado às informações. Segundo ele, certos atores têm um poder de organização e de recursos maior do que outros. Neste caso, aqueles que estão em situação de desvantagem terão que contar com protetores que disponibilizem os recursos necessários para àqueles que precisam, mas o autor defende a ideia de que, no caso de ambos terem as mesmas ideias, não existe razão para achar que pode haver um comprometimento na neutralidade do pensamento em função da cooperação.

O filósofo afirma que, pelo fato de existir uma parcela do público que é leiga, não significa que as discussões sejam prejudicadas e as decisões tenham resultados deturpados. os atores podem ser identificados das seguintes formas: aqueles que se aproveitam da esfera pública e aqueles que surgem nela; as identidades dos atores não estão dadas pelo conteúdo de seus discursos, mas através da maneira como são identificados, ou seja, aquele que surge a partir de uma esfera pública, precisa criar uma identidade, precisa se posicionar em relação ao que está dado, já aquele que existe independente da esfera pública e que se aproveita dela, tem sua identidade independente da mesma.

Arendt e Habermas concordam em suas críticas à sociedade moderna, unindo ação e discurso pela vontade comum, dirigi-las a um tipo de racionalidade ou comportamento alheio a esfera pública é o que a descaracteriza integralmente. Para Arendt, o destaque dado às invenções, colocadas sobre o pedestal das maiores realizações humanas, não poderia deixar de trazer junto a troca da ação pela racionalidade técnica, desintegrando o conjunto agir e falar da genuína realização humana: a política. Habermas afirma a necessidade da ação/comunicativa enlaçar-se ao processo do advento do social (modernidade), dele tirando os elementos de 
significado e validade, que tornam possíveis os consensos, ao mesmo tempo em que se rompe com uma racionalidade tecnicista e esfaceladora do espaço político e público.

\section{CONSIDERAÇÕES FINAIS}

Compreender os conceitos de Arendt e Habermas como marcos históricos de discussões das fronteiras entre público e privado, qual sua função e que troca existe com a esfera privada é essencial ao caminho percorrido nessa pesquisa. Arendt nos lembra das possibilidades mesmo que pelo modelo grego, que o espaço público tem de ser de discussão e ação em prol de uma democracia, abordar a liberdade e a ação política que o homem deveria ter, e que o ser humano não é politico sozinho, representa um resgate ao que parece ser primordial á prática de alteridade e responsabilidade que temos pelo outro e por nós.

Enquanto Arendt identifica advento do social, que em primeira instância pode ter representado um retrocesso e marginalização do sujeito politico, Habermas resgata esse ponto e vislumbra um novo olhar de superação ao que também chamamos de modernidade, que representa pra esse debate um novo sistema de deliberações e ações sobre esses limites e as necessidades que precisam vir a público, Habermas então reestrutura o 'ideal' de Arendt e o chama a convergir com uma ética do discurso, elaborando assim novos desdobramentos da dicotomia do público e privado. Quando Arendt e Habermas tecem essas análises na filosofia, eles abrem caminho para o que vem a ser teoria critica feminista, que por todo processo de negação histórica, no campo das ciências e tecnologia, na invisibilização do sujeito feminino, estoura como um processo de estudo intenso de como se faz filosofia e como se faz critica para a contribuição na democracia de recorte de quem vive as margens do espaço público.

\section{NOTAS}

1 "Praça" pública se caracterizava como um espaço construído, permanente e fixo, que, tinha também um sentido político - era o lugar onde se deliberavam assuntos importantes para a vida dos cidadãos e da sociedade como um todo.

${ }^{2}$ Aristóteles afirmava que o homem normal é um zoon - politikon, ou seja, um animal (zoon) político (politikon), um ser que vive para a cidade, para a sociedade. Quem vivia isolado, ou era uma besta (totalmente animal) ou um deus (totalmente racional).

${ }^{3}$ Em A Condição Humana (2014), Arendt designa com a expressão vita activa, três atividades humanas essenciais : labor, obra e ação ,cada uma dessas atividades corresponde a uma das condições básicas nas quais a vida foi dada ao homem na Terra. Labor corresponde ao processo biológico do corpo humano e tem como condição humana a própria vida. A obra corresponde ao artificialismo da existência humana, produz um mundo artificial de coisas, distintamente diferente de qualquer ambiente natural, e tem como condição humana a mundanidade. A ação é correspondente à condição humana da pluralidade, não é mediada pelas coisas para colocar os homens em contato uns com os outros. Todas as atividades da vita activa possuem alguma relação com a política, no entanto a pluralidade é a condição de toda vida 
política. A pluralidade liga-se ao fato de que são os homens, e não o homem, que habitam a Terra.

\section{REFERÊNCIAS BIBLIOGRÁFICAS}

ARENDT, H. A Condição Humana. 12. ed. Rio de Janeiro: Forense Universitária, 2014.

HABERMAS, J. Direito e Democracia: entre facticidade e validade. Rio de Janeiro: Tempo Brasileiro, 1997
SANTOS, V. Soraya. A relação entre o público $e$ privado: um estudo inicial sobre o pensamento de Hannah Arendt. In: Inter-Ação, v. 37, n. 2, p. 223-235, jul./dez. 2012.

TELLES, V. Silvia. Espaço público e espaço privado na constituição do social: notas sobre o pensamento de Hannah Arendt. In:Tempo Social, v. 2, n. 1, p. 23-48, jan. 1990.

GONZAGA, A.C.M.; COUTO, D.R.T. A Dicotomia do Público/Privado em Hannah Arendt e Jürgen Habermas: Interações e Reflexões a Luz da Teoria Crítica Contemporânea.

Complexitas - Rev. Fil. Tem. Belém, v. 2, n. 2, p. 18-33, jul./dec. 2017. Disponível em:< http://www.periodicos.ufpa.br/index.php/complexitas/article/view/5460>. Acesso em: 07 de janeiro de 2019. 